\title{
PERCEIVED MEDIA USAGE AMONG PARENTS AND ADOLESCENT'S MENTAL HEALTH: A CORRELATIONAL STUDY
}

\author{
Dr. B. S. Parimal
}

\begin{abstract}
The study aimed to study the correlation between perceived media usage among parents and adolescent's Mental Health. A Survey Research Questionnaire was used to collect data. Perceived media usage among the parents questionnaire was developed based on review of literature and was face validated by the experts and Mental Health Inventory-38 were used for data collection. Total 200 adolescents were taken as sample from different schools of Vadodara. Pearson's product movement test was used to study correlation between perceived media usage among parents and adolescent's Mental Health. Result shows that adolescents who perceive high media usage among parents have poor mental-health. The research will implicate to enhance mental health of school students.
\end{abstract}

Keywords : perceived media usage among parents, Mental Health and adolescents

\section{Introduction}

Mental health is a state of well-being in which the individual realizes his or her own abilities, can cope with the normal stresses of life, can work productively and fruitfully, and is able to make a contribution to his or her community (WHO, 2004). Parents play a vital role in maintaining a homeostasis within the child. Toma and Hancock (2013) found that Facebook help satisfy individuals' need for self-worth and self-integrity. The most popular reasons for using social media included staying in touch with current friends and family, although other reasons emerged as well: making new friends, reading comments by celebrities and politicians, and finding potential romantic partners. Tozandehjani, Tavakolizadeh, and Lagzian (2011), studied the Parenting Style effect on students self-efficacy and mental health andfound that parenting styles significantly influenced students self-efficacy. Niaraki 
and Rahimi (2013) studied the relation between Self- Esteem, Mental Health and Quality of Life and Parenting Styles among high school students of Iran and reported that, parenting style has no relation to social mental health.

Mental health is a state of complete physical, mental and social well-being and not merely the absence of disease or infirmity (WHO, 2001b). Young adults are at a high risk of developing mental health problems as they experience emerging adulthood. These same young adults are the most active users of social media, which has a distinct connection with mental health problems. Mental health is about improving competencies of individuals and communities and letting them to achieve their self-determined goals. Mental health should be of utmost concern to all of us, and mot the only for those who suffer from a mental disorder. Mental health problems affect society as a whole, and does not just affect small, isolated segment. No group is immune to mental disorders, but the risk is higher among the poor, homeless, the unemployed, persons with low education, victims of violence, migrants and refugees, indigenous populations, children and adolescents, abused women and the neglected elderly. For all the individuals, mental, physical and social health is closely interwoven, vital strands of life. As our understanding of this interdependent relationship grows, it becomes much more apparent that mental health is crucial to the overall well-being of individuals, societies and countries. Unfortunately, in most parts of the world, mental health and mental disorders are not given that much importance as physical health anywhere.

Ono et al. (2011) concluded that the amount of face-to-face social interaction improve mental health. Ransford (1982) suggests that the improvements in mental health face to face conversation, mutual support and social relationships are necessary. Family members are often the caregivers for people with mental disorders. They provide emotional and physical support, and often bear the financial expenses associated with mental health treatment and care. It is estimated that one in four families has at least one member who suffer from a mental or behavioural disorder. Moreover distress of seeing a loved one disabled due to a mental disorder, family members are also exposed to the stigma and discrimination associated with mental ill health. Rejection by friends, relatives, neighbours and the community as a 
whole can increase the family's sense of isolation, leading to restricted social activities, and the denial of equal participation in normal social networks. The failure of society to acknowledge mental disorders on affected families means that very little support is available to them. Expenses for the treatment of mental illness have to be borne by the family because they are generally not covered by the State or by insurance. Family members may need to set aside a big amount for any mental disorder. Unfortunately, the lack of understanding on the part of most employers, and the lack of special employment schemes to address this issue, sometimes render it difficult for family members to gain employment or to hold on to an existing job, or they may suffer a loss of earnings due to days taken off from work. Kuss and Griffiths (2011) concluded that extensive media does reduce real life social community participation and often causes relationship problems. British adults expressed that they felt worried or uncomfortable when they could not access their email or social network sites (Anxiety UK, 2012).

Parents, who apply hostile approaches to resolve their conflicts, have children with more symptoms of antisocial behaviour. Further studies in this field revealed that separation from parents and poor communication with children have a relationship with the degree of depression and aggressive behaviour of the children. The child development research community has been a forerunner in investigating this space and reported uniformly discouraging findings. Radesky and colleagues collected observational data from 55 families eating together at fast food restaurants. They documented the ramifications of adults' constant connectivity, uncovering thematic distractibility, irritability, and inability to be interrupted among those using phones. Other work has reported that adults respond inappropriately to children when they are distracted by devices and that children experience adults' phone distraction as alienating and emotionally dissatisfying. Researchers have expressed concern that adults' phone use while caring for children is displacing play-based adult child interactions. As play and face-to-face interactions are the bedrock of young children's social learning and language acquisition, adults' phone-use practices are potentially disruptive to critical elements of children's early learning environments. Despite these early investigations, work in this area is still in its infancy and many of 
these concerns speculative. To date, no authoritative body has published specific recommendations or evidence-based guidance for parents on this topic.

In the $21^{\text {st }}$ century with enormous advancement of technology and media people are encouraged to be a part of this advancement and are curious to learn all the new interesting ways of socialising and keeping themselves aware of things around them. It is a well-established fact that children require complete emotional support, affection and attention of their parents at all times during their developmental stages to satisfy their curiosity and queries as well. Since last 20 years there has been seen a gradual structural change in the families in India from joint to nuclear as well. Parents play a vital role in maintaining a homeostasis within the child.

\section{Objective:}

To study whether there is any correlation between perceived media usage by parents and Adolescent's mental health.

\section{Hypothesis}

There will be a significant negative correlation between perceived media usage among parents and Adolescent's Mental Health.

\section{METHOD}

\section{Sample}

Total 200 students both males and females of classes 8 to 11 of the age 13 to 17 years were taken as sample from the English medium schools in Vadodara. Inclusion criteria were Students should be from English medium school. Students can be male and female of age 13 to 17 years. Exclusion criteria were students from Guajarati or Hindi medium and students who are mentally and physically challenged. Out of 200 samples $90(45 \%)$ are males and $110(55 \%)$ are females.

\section{Research Design}


A Survey questionnaire was used to collect data. The survey questionnaire was given to the students and they were instructed to fill the questionnaire carefully. In such way data was collected and analysed. The survey research is primarily interested in assessing the characteristics of the whole population. Perceived media usage among the parents questionnaire was developed based on review of literature and was face validated by the experts and Mental Health Inventory-38 were used for data collection.

\section{Tools}

\section{Perceived media usage among the parents a questionnaire}

Perceived media usage among the parents a questionnaire was developed based on review of literature and was face validated by the experts. It is a five point scale 1 being never 2 being rarely 3 being sometimes 4 being often and 5 being always. There are 20 items in total. There are reverse items as well. The demographic details include name (optional), age, standard, number of media resources used by parents, guardian of the child, Single parent and if the father and mother are both working parents. Pilot study was done on 33 students of age varying from 14 to 18 years .Internal Reliability (Chronbach alpha) was checked. It was found to be reliable 0.79 .

\section{The mental health}

The mental health questionnaire was borrowed from the mental health inventory (MHI 38) (The Mental health inventory (MHI-38, 2003), designed to measure general psychological distress and well-being for the general population. Measures include both positive aspects of well-being (such as cheerfulness, interest in and enjoyment of life), negative aspects of mental health (example: anxiety and depression). It is a Self-Rated Questionnaire having 38 items which describe symptoms or states of mind. The original Mental Health Inventory 38 has reported 0.93 Chronbach alpha Reliabilty. Current study reliability is 0.81

\section{Procedure}


List of approachable Schools was made and permission letters were prepared. Permission was taken from the institutes. After the permission was granted, the students were briefed about the idea of this study. Then the questionnaire was given to those students who fall in the research criteria and the data was collected. Based on their responses the data was analysed and the conclusions were made. Pearson's product movement test was used to study correlation between adolescent's Mental Health and perceived media usage among parents.

\section{Result and Discussion}

Pearson's product movement test was used to study correlation between adolescent's Mental Health and perceived media usage among parents and result is below:

Table:1 correlation between mental health and Media usage among parents

\begin{tabular}{|c|c|c|c|c|c|c|c|}
\hline $\begin{array}{l}\text { Pearson } \\
\text { Correlation }\end{array}$ & $\begin{array}{l}\text { Media } \\
\text { usage } \\
\text { amon } \\
\text { g } \\
\text { parent } \\
\text { s }\end{array}$ & Anxiety & $\begin{array}{l}\text { Depres } \\
\text { sion }\end{array}$ & $\begin{array}{l}\text { Loss of } \\
\text { emotio } \\
\text { nal \& } \\
\text { behavio } \\
\text { ural } \\
\text { control }\end{array}$ & $\begin{array}{l}\text { General } \\
\text { Positive } \\
\text { effect }\end{array}$ & $\begin{array}{l}\text { Emoti } \\
\text { onal } \\
\text { Ties }\end{array}$ & $\begin{array}{l}\text { Life- } \\
\text { Satisf } \\
\text { actio } \\
n\end{array}$ \\
\hline $\begin{array}{l}\text { Media usage } \\
\text { among } \\
\text { Parents }\end{array}$ & 1 & & & & & & \\
\hline Anxiety & $0.385^{\star *}$ & 1 & & & & & \\
\hline Depression & $0.576^{* \star}$ & $0.510^{* \star}$ & 1 & & & & \\
\hline $\begin{array}{lr}\text { Loss } & \text { of } \\
\text { emotional } \quad \& \\
\text { behavioural } \\
\text { control }\end{array}$ & $0.474^{* *}$ & $0.525^{\star *}$ & $0.689^{* *}$ & 1 & & & \\
\hline $\begin{array}{l}\text { General } \\
\text { Positive } \\
\text { Effect }\end{array}$ & $-0.498^{* *}$ & $-0.294^{* *}$ & $-0.596^{\star *}$ & $-0.328^{* *}$ & 1 & & \\
\hline Emotional ties & $-0.155^{*}$ & -0.093 & $-0.183^{*}$ & 0.070 & $0.522^{* *}$ & 1 & \\
\hline
\end{tabular}


Towards Excellence: An Indexed, Refereed \& Peer Reviewed Journal of Higher Education /

Dr. B.S. Parimal/ Page 51-61

\begin{tabular}{|l|l|l|l|l|l|l|l|}
\hline $\begin{array}{l}\text { Life- } \\
\text { Satisfaction }\end{array}$ & $-\mathbf{0 . 4 0 9 ^ { * * }}$ & $-0.240^{* *}$ & $-0.458^{* *}$ & $-0.481^{* *}$ & $0.432^{* *}$ & $0.147^{*}$ & 1 \\
\hline
\end{tabular}

${ }^{* *}$ Correlation is significant at 0.01 level; $\quad{ }^{*}$ Correlation is significant at 0.05 level

The result indicates that there is significant positive correlation between Anxiety in adolescents and Media usage among parents. It means that adolescents who perceive higher media usage among parents they have high anxiety. Media usage among parents therefore shows a negative effect on self-esteem of adolescents. There is significant positive correlation between perceived media usage among parents and Anxiety in adolescents. It means that adolescents who perceive higher media usage among parents have high anxiety .If the media usage among parents will be less than the anxiety in adolescents too will be reduced. There is significant positive correlation between perceived media usage among parents and Depression in adolescents. It means that adolescents who perceive higher media usage among parents they feel high depression. There is significant positive correlation between perceived media usage among parents and loss of emotional and behavioural control in adolescents. It means that adolescents who perceive higher media usage among parents have higher loss of behaviour and emotional control. There is significant negative correlation between perceived media usage among parents and general positive effect in adolescents. It means that adolescents who perceive higher media usage among parents have low general positive effect. There is significant negative correlation between perceived media usage among parents and Emotional ties in adolescents. It means that adolescents who perceive higher media usage among parents have weak emotional ties. There is significant negative correlation between perceived media usage among parents and Life Satisfaction in adolescents. It means that adolescents who perceive higher media usage among parents have low life satisfaction.

The hypothesis assumes that there will be significant negative correlation between perceived media usage among parents and mental health. The result (table 1) indicates all the dimensions of mental health taken for the study. Anxiety, Depression and Loss of behavioral and emotional control are significantly positively correlated with perceived media usage among parents. More the perceived usage of media by parents more the anxiety, depression and loss of behavioral and emotional control. The General positive effect, emotional ties and life satisfaction are the other three 
dimensions of the six dimensions of mental health which are significantly negatively correlated with perceived media use among parents. When parents use a lot of media the adolescents have lower general positive effect, lower emotional ties and lower life satisfaction as well. Therefore according to table 1.1 the first hypothesis is accepted.

Kuss and Griffiths, research unit - Psychology Division Trent University U.K, (2008) did a study on Extensive media usage and online social networking. The research concluded that extensive media does reduce real life social community participation and often causes relationship problems. A recent study found that many British adults expressed that they felt worried or uncomfortable when they could not access their email or social network sites (Anxiety UK, 2012). A study of American university students found that more intense Facebook use predicted increased loneliness (Lou et al., 2011). People who spend more time in sedentary behaviours (like social media use) spend less time for face-to-face social interaction and physical activity, which both have been proven to be helpful against mental disorders (Martinsen, 2008). Ono et al. (2011) found that the amount of face-to-face social interaction was positively correlated to improved individual mental health. Ransford (1982) suggests that the improvements in mental health face to face conversation, mutual support and social relationships are necessary. The parent's relationship to the adolescent contributes to the self-worth of the adolescent. Particularly parent support is an important factor for adolescents to perceive themselves as important and valuable (Lök \& Lök, 2016).

\section{Conclusion:}

Perceived media usage among parents has a positive effect on negative mental health (i.e. anxiety, depression and loss of behavioural and emotional), i.e. adolescents who perceive higher media usage among parents develop heightened anxiety, depression and loss of behavioural and emotional control. Perceived media usage among parents has a negative effect on positive mental health (i.e. general positive effect, emotional ties and life satisfaction), i.e. adolescents who perceive higher media usage among parents have lowered general positive effect, emotional ties and life satisfaction. The study implies in areas of Parental counselling where 
Towards Excellence: An Indexed, Refereed \& Peer Reviewed Journal of Higher Education /

Dr. B.S. Parimal/ Page 51-61

emphasis is given on real life relationships and social communication and interaction.

\section{Limitations of study:}

Limitations of the research are there is no equal number of male and female adolescents. For this research the sample selection did not consider the socioeconomic status of adolescents. The samples collected were only from the private schools in Vadodara. For the research the sample chosen was only from English medium schools of Vadodara.

\section{Implication:}

The research will imply in following area:

- Improve mental health of adolescent

- Parenting training and workshop

- Developing good relationship between parent and children

- Add in current theory and knowledge of Media Psychology 
Towards Excellence: An Indexed, Refereed \& Peer Reviewed Journal of Higher Education /

Dr. B.S. Parimal/ Page 51-61

\section{References:}

Anxiety UK (2012, July 9). Anxiety UK study finds technology can increase anxiety. Retrieved from http://www.anxietyuk.org.uk/2012/07/for-some-with-anxietytechnology- canincrease-anxietyl

Kuss, D.J. \& Griffiths, M.D. (2011). Excessive online social networking: Can adolescents become addicted to Facebook? Education and Health, 29, 63-66. (Accessed 15th August 2017). Retrieved from http://sheu.org.uk/sites/sheu.org.uk/files/imagepicker/1/eh294mg.pdf

Lök, N. \& Lök, S. (2016). The relationship between the physical activity levels and cognitive status of the elders. Yeni Symposium 54: 21-24.

Lou, S. J., Guo, Y. C., Zhu, Y. Z., Shih, R. C. \& Dzan, W. Y. (2011). Applying computerassisted musical instruction to music appreciation course: An example with Chinese musical instruments. The Turkish Online Journal of Educational Technology, vol. 10, no. 1, pp. 45- 57, from: http://www.tojet.net/articles/1015.pdf

Martinsen, E.W. (2008). Physical activity in the prevention and treatment of anxiety and

Medicine and Science in Sports and Exercise, 4, 1-10.

Mental Health Inventory - 38 (MHI - 38). (2003). MHI - 38. The RAND Corporation. retrieve from https://www.amhocn.org/sites/default/files/publication_files/mental_health_inventory.p df

Niaraki, F. R \& Rahimi, H. (2013).The impact of authoritative, permissive and authoritarian behavior of parents on self-concept, psychological health and life quality. European Online Journal of Natural and Social Sciences, 2(1), 78-85.

Ono, E., Nozawa, T., Ogata, T., Motohashi, M., Higo, N., Kobayashi, T., Ishikawa, K., Ara,

Orth, U., Robins, R. W., \& Meier, L. L. (2009). Disentangling the effects of low self-esteem and stressful events on depression: Findings from three longitudinal studies. Personality Processes and Individual Differences, 97, 307-321.

Orth, U., Robins, R. W., \& Roberts, B. W. (2008). Low self-esteem prospectively predicts depression in adolescence and young adulthood. Personality Processes and Individual Differences, 95, 695-708. 
Towards Excellence: An Indexed, Refereed \& Peer Reviewed Journal of Higher Education /

Dr. B.S. Parimal/ Page 51-61

Ransford, C.P. (1982). A role for amines in the antidepressant effect of exercise: a review.

Retrieved from http://www.cnbc.com/id/100275798\#.

Singh. A.K. (2013). Tests, Measurements and Research Methods in behavioural

Science. Bharti Bhawan Publications, New Delhi.

Toma, C. and Hancock, J.T. (2013). Self-Affirmation Underlies Facebook Use. Psychology Bulletin, 39(3), 321-331.

Tozandehjani, H, Tavakolizadeh, J, \& Lagzian, Z. (2011). The effect of parenting styles on selfefficacy and mental health of students. The Horizon of Medical Sciences, 17(2), 56-64.

WHO (2001b). Basic documents, 43rd edn. Geneva, World Health Organization.

World Health Organization. (2004 ). romoting mental health: concepts, emerging evidence, practice (Summary Report) Geneva: World Health Organization

\section{Dr. B. S. Parimal \\ Assistant Professor, \\ Department of Psychology, Faculty of Education and Psychology, The Maharaja Sayajirao University of Baroda Vadodara, Gujarat, India-390002 drbsparimal@gmail.com}

